\title{
GSP4PDB: a web tool to visualize, search and explore protein-ligand structural patterns
}

Renzo Angles ${ }^{1,2^{*}}$, Mauricio Arenas-Salinas ${ }^{3,4}$, Roberto García ${ }^{2,4}$, Jose Antonio Reyes-Suarez ${ }^{3,4}$ and Ehmke Pohl $\left.\right|^{5,6}$

From 6th International Work-Conference on Bioinformatics and Biomedical Engineering

Granada, Spain. 25-27 April 2018

\begin{abstract}
Background: In the field of protein engineering and biotechnology, the discovery and characterization of structural patterns is highly relevant as these patterns can give fundamental insights into protein-ligand interaction and protein function. This paper presents GSP4PDB, a bioinformatics web tool that enables the user to visualize, search and explore protein-ligand structural patterns within the entire Protein Data Bank.

Results: We introduce the notion of graph-based structural pattern (GSP) as an abstract model for representing protein-ligand interactions. A GSP is a graph where the nodes represent entities of the protein-ligand complex (amino acids and ligands) and the edges represent structural relationships (e.g. distances ligand - amino acid). The novel feature of GSP4PDB is a simple and intuitive graphical interface where the user can "draw" a GSP and execute its search in a relational database containing the structural data of each PDB entry. The results of the search are displayed using the same graph-based representation of the pattern. The user can further explore and analyse the results using a wide range of filters, or download their related information for external post-processing and analysis.
\end{abstract}

Conclusions: GSP4PDB is a user-friendly and efficient application to search and discover new patterns of protein-ligand interaction.

Keywords: PDB, Protein-ligand interaction, Structural patterns, Big data

\section{Background}

In the context of protein engineering and biotechnology, structural patterns are three-dimensional structures that occur in biological molecules, such as proteins or nucleid acid, and are key to understand their functionality [1]. The discovery and characterization of structural patterns is an important research topic as it can give fundamental

\footnotetext{
*Correspondence: rangles@utalca.cl

This is an extended version of the article "A graph-based approach for querying protein-ligand structural patterns", presented at the 6th International Work-Conference on Bioinformatics and Biomedical Engineering (IWBBIO'2018).

'Department of Computer Science, Universidad de Talca, Camino Los Niches Km 1, Curicó, Chile

${ }^{2}$ Millennium Institute for Foundational Research on Data, Santiago, Chile Full list of author information is available at the end of the article
}

insight into protein function, and represents an important tool to decipher the function of novel proteins $[2,3]$.

We concentrate our interest on structural patterns representing protein-ligand interactions [4]. Ligands are small molecules (such as ATP, drug and metal) that can interact, bind and control the biological function of proteins. Finding common binding sites in weakly related proteins may lead to the discovery of new protein functions and to novel ways of drug discovery [5].

The study of the specific interaction of a protein with a ligand is an active research field because of the implications this has in the overall understanding of the structure and function of proteins, and in particular in the fast-growing area of rational drug design [6]. Particularly, structure-based drug design/discovery is one of

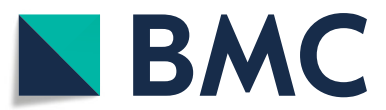

(C) The Author(s). 2020 Open Access This article is distributed under the terms of the Creative Commons Attribution 4.0 International License (http://creativecommons.org/licenses/by/4.0/), which permits unrestricted use, distribution, and reproduction in any medium, provided you give appropriate credit to the original author(s) and the source, provide a link to the Creative Commons license, and indicate if changes were made. The Creative Commons Public Domain Dedication waiver (http://creativecommons.org/publicdomain/zero/1.0/) applies to the data made available in this article, unless otherwise stated. 
the computer-aided methods by which novel drugs are designed or discovered based on the knowledge of 3D structures of the relevant specific targets [7-9].

The importance of structural patterns can be exemplified by the Zinc finger motif that is widely found in DNA binding proteins including many eukaryotic transcription factors $[10,11]$. Although proteins containing this motif perform a wide range of functions in various cellular processes, they all rely in the same underlying structural pattern [12].

To the best of our knowledge, there is no standard way to represent and search protein-ligand structural patterns (like the Zinc Finger motif) in structure databases. One way to represent patterns is to use a textual format. For instance, PROSITE defines the PA line notation [13] which allows to represent the classical zinc finger pattern as the text string $\mathrm{C}-\mathrm{x}(2,4)-\mathrm{C}-\mathrm{x}(12)-\mathrm{H}-\mathrm{x}(2,6)-\mathrm{H}$. A similar notation can be found in several articles [11, 14, 15]: $\mathrm{CX}_{2-4} \mathrm{CX}_{12} \mathrm{HX}_{2-6} \mathrm{H}$. Note that both notations are based on primary structure alone, so they are restricted to express sequence patterns (i.e. a sequence of amino acid symbols).

There are only limited tools available to search and analyse these patterns in the sequence and structural databases. They rely on the input of simple numerical values and the results are usually represented as tables or statistical charts such as histograms. Therefore, the searches are complicated and cumbersome to visualise making the exploration of structural pattern difficult and non-intuitive. Different types of visual representations used by current tools and systems are described in the section about Related Work.

Considering the problems identified above, we propose a graph-based model for representing structural patterns. Specifically, any protein-ligand structural pattern can be described as a graph whose nodes describe amino acids or ligands, and the edges represent their relationships. Based on this model we have developed GSP4PDB, a web application that enables the non-expert user to design, search and analyse protein-ligand structural patterns inside the Protein Data Bank (PDB) [16].

\section{Protein-ligand structural patterns}

Proteins are structurally complex and functionally sophisticated molecules, whose existence is essential to all forms of life with their wide ranging roles in all organisms [17].

There are four levels of organization in the structure of a protein. The primary structure refers to the sequence of amino acids, which are linked by peptide bonds to form polypeptide chains. Polypeptide chains can fold into regular structures such as the alpha helices and beta sheets. These substructures, stabilized by regular $\mathrm{H}$-bonding between the main chain atoms, conforms the secondary structure of the protein. Tertiary structure refers to the full three-dimensional organization of one polypeptide chain. Finally, if a particular protein is formed by more than one polypeptide chain, the complete structure is designated as the quaternary structure [18].

The notion of structural pattern is used to describe a three-dimensional "structure" or "shape" of motifs such as ligand binding sites in the protein [19]. The same structural pattern can occur in a group of proteins with a given frequency and satisfying specific criteria (e.g. atomic distance, composition, connectivity, etc.). There are several types of structural patterns, but we concentrate on those representing protein-ligand interactions [4].

We define a protein-ligand structural pattern as the combination of a ligand and a group of amino acids, whose three-dimensional distribution could be determined by different types of relationships, including the distance between two amino acids, the distance between an amino acid and the ligand, and the order or precedence (in the sequence) of an amino acid with respect to other amino acid.

For instance, a Cys2His2 zinc finger [14] is a proteinligand structural pattern where one $\mathrm{Zn} 2+$ ion (the ligand) is tetrahedrally coordinated by cysteine and histidine residues (the amino acids). Figure 1 shows a three-dimensional representation of the Cys2His2 zinc finger [11].

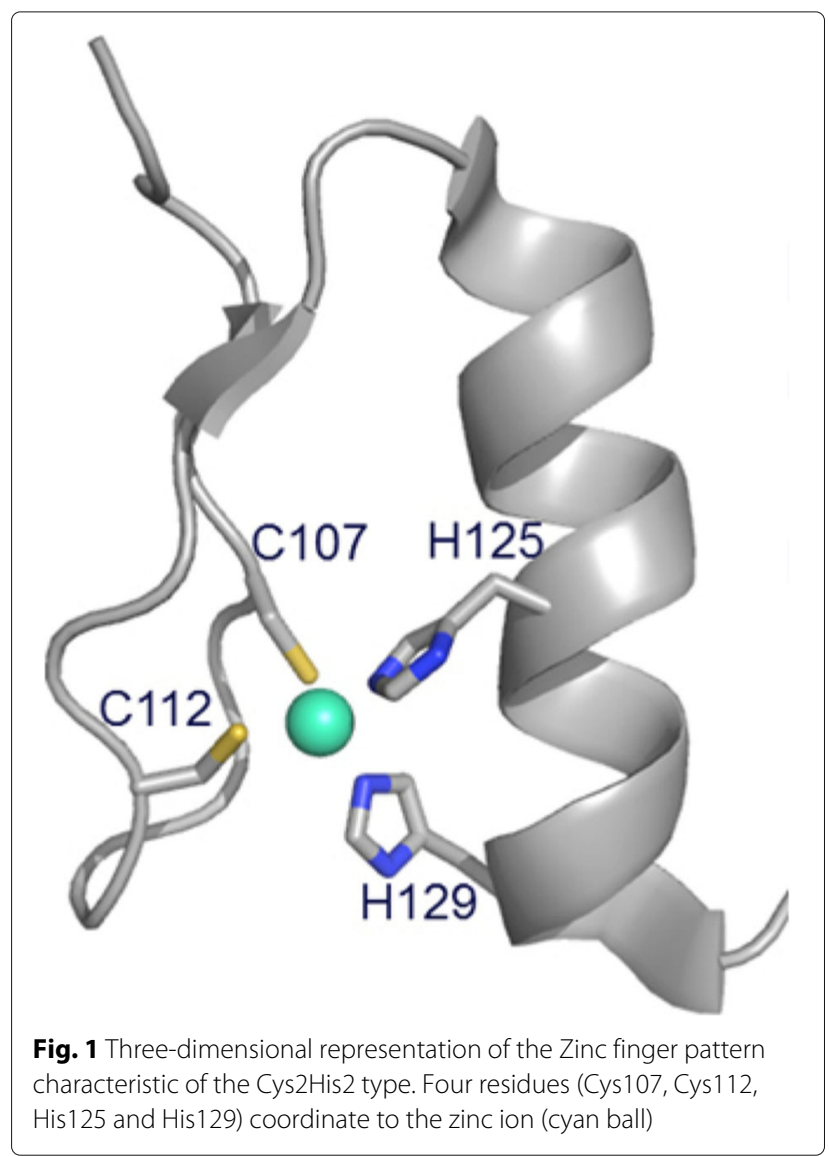


A schematic representation of the $\mathrm{Zn} 2+$ binding site of a zinc finger is shown in Fig. 2. According to the PROSITE notation [20], the above pattern can be represented with the text expression $\mathrm{x}(5)-\mathrm{C}-\mathrm{x}(3)-\mathrm{C}-\mathrm{x}(12)-\mathrm{H}-$ $\mathrm{x}(3)-\mathrm{H}-\mathrm{x}(5)$. Importantly, this representation refers to the primary structure only.

On the one hand, the schematic representation is sufficient to show the protein-ligand interaction (including some structural details). On the other hand, the textual representation provides a simple syntax to describe the structure of the sub-sequence participating of the binding site. However, the textual description does not contain any detail such as distances and geometry. In addition, the single-letter amino-acid representation is mainly used by bioinformaticians and hence limits its general use.

In order to circumvent the limitations described above, we propose the use of graphs as a simple and intuitive way to represent and visualize structural patterns.

\section{Graph-based structural patterns}

In general terms, a graph-based structural pattern (GSP) is a graph where the nodes represent protein's components (i.e. amino acids and ligands) and the edges represent structural relationships (e.g. distance between amino acids). For instance, Fig. 3 shows a GSP that corresponds to a $\mathrm{Zn2}+$ binding site in a GATA-type zinc finger. GATA factors coordinate cellular maturation with proliferation arrest and cell survival, therefore they play important roles in human cancers [21].
The textual representation of a GATA zinc finger [22] is given in PROSITE by the expression $C-x(2)-$ $C-x(17)-C-x(2)-C$. This textual representation denotes that a single zinc ion is coordinated by 4 cysteine residues such that, between the first and the second cysteine there are two amino acids of any kind, 17 amino acids between the second and third, and again two amino acids of any kind between the third and the fourth.

Formally, a graph-based structural pattern is a labeled property graph, i.e. a labeled graph where nodes and edges can contain key-value pairs representing their properties (or attributes). Four types of nodes are allowed: amino-acid-nodes, any-amino-acid-nodes, ligand-nodes and any-ligand-nodes. Additionally, nodes can be connected by three types of edges: distance-edges, next-edges and gap-edges.

Nodes are drawn as ellipses whose label (inside a square) determine their type. An amino-acid-node represents a specific residue, whose name is defined by the property name. An any-amino-acid-node represents the occurrence of any amino acid (as a variable). Each any-amino-acid-node includes the property "polarity", whose value can be "any", "non-polar", "polar uncharged", "positively charged" or "negatively charged". A ligand-node represent the ligand of the pattern, whose 3-letter code is defined by the property "code". An any-ligand-node represents any ligand (similar to an any-amino-acid-node).

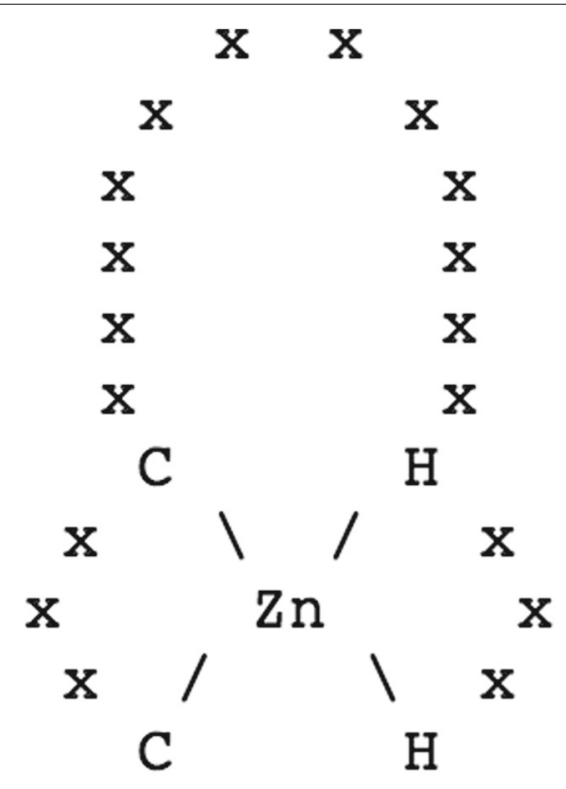

$\mathrm{X} \times \mathrm{X} \times \mathrm{X}$

$\mathrm{X} \times \mathrm{X} \times$

Fig. 2 A schematic representation of a Zinc Finger found in PROSITE 


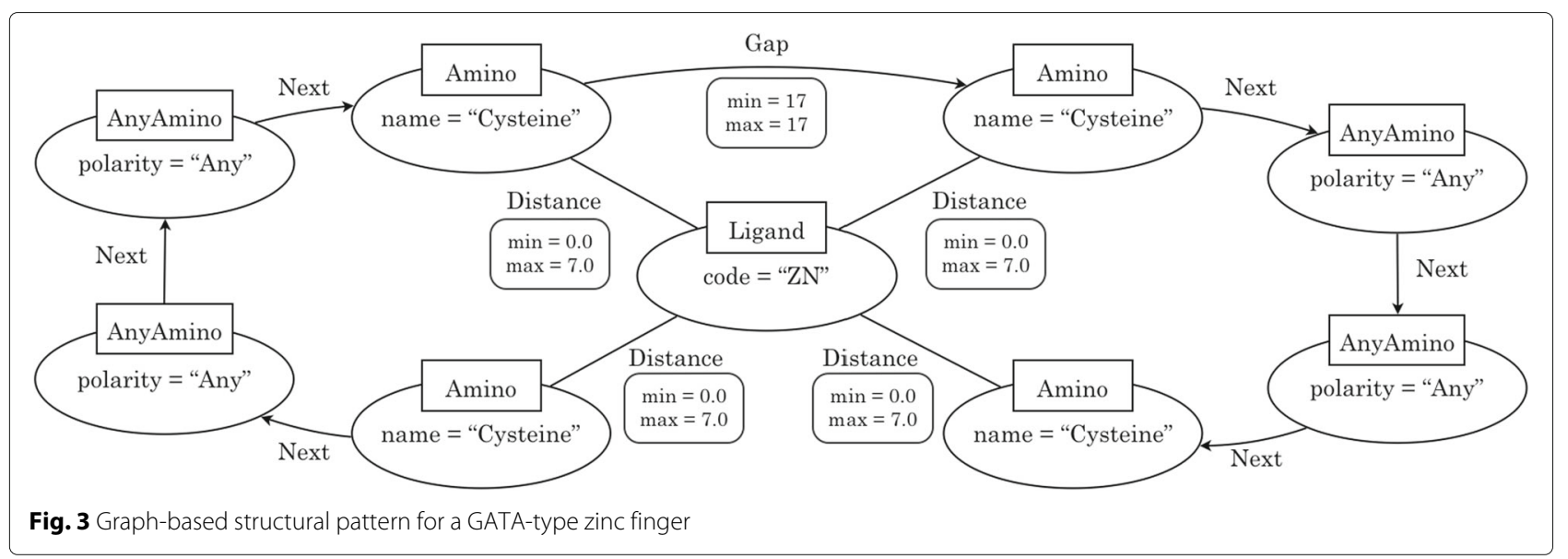

Edges are labeled with their type (distance, next or gap), and can be directed (next-edges and gap-edges) or undirected (distance-edges). A distance-edge is an undirected edge which represents the distance relationship between two amino acids, or between an amino acid and the ligand. A distance-edge includes the properties $\min$ and $\max$, which allow to define the minimum and maximum distance expressed in Angstroms (a distance range between $0.5 \AA$ and $7 \AA ̊$ ). Given two amino acids $X$ and $Y$ (specific or any), a next-edge allows to specify that $X$ follows $Y$ in the sequence, and a gap-edge represents the occurrence of a given number of amino acids in the sequence between $X$ and $Y$. The number of amino acids is defined by the properties $\min$ and $\max$, such that $\min >0$, $\max \geq \min$, and $\max =*$ represents an undefined number.

Note that our graph-based representation is a simple and intuitive way to describe and recognize the twodimensional structure of a protein-ligand pattern. Importantly, the model proposed here could be extended to represent other types of structural patterns.

\section{Implementation}

Using the graph-based structural patterns, we have developed GSP4PDB, a bioinformatics tool that allows the user to analyse protein-ligand interactions within the entire protein data bank. GSP4PDB is formed by three main elements: gsp4pdb-parser, a java tool which extracts and processes data from PDB coordinate files; a relational database (PostgreSQL) which is used to store and manage protein data; and a web application which provides a graphical interface to visualize, search and explore graphbased structural patterns.

\section{Protein data extraction and pre-processing}

GSP4PDB was designed to work using data obtained from the Protein Data Bank (PDB) [16]. Therefore, we have developed gsp4pdb-parser, a command-line java application which allows to process PDB files and export the data to a relational database system.

We use rsync to maintain a local copy of the entire protein data bank. So, each time gsp4pdb-parser is executed, the relational database is updated with the latest proteins released in the main PDB repository. The current version of gsp4pdb-parser is restricted to process files encoded using the PDB format (".pdb, ".ent or ".ent.gz).

To execute gsp4pdb-parser, the user must specify a local directory where the PDB files are stored. Hence, gsp4pdbparser explores the directory (recursively) and prepares (internally) a list of available PDB files. Such list is filtered according to the proteins available in the relational database, whose corresponding files were processed previously. Optionally, the user can specify a list of protein IDs to be processed.

For each file of the filtered list, gsp4pdb-parser reads the file using biojava [23] and creates an object model of the protein. The main classes of the model are Protein, SChain, Aminoacid, AminoStandard, AminoStandardList, Ligand, AtomAmino, AtomLigand and Distance. Although a protein can contain many chains, at the moment only the chain with the largest number of amino acids is being processed for simplicity.

Note that a PDB file does not contain explicit information about specific atomic distances. In order to improve the performance of the system, which relies on complex join operations for the relational database, some distances are pre-computed in the initial phase.

Therefore, during the construction of the object model two distance measures are pre-computed: distance aminoamino and distance ligand-amino. The distance between two amino acids $A$ and $A^{\prime}$, is calculated as the minimum distance between each pair of atoms $\left(a_{i}, a_{j}\right)$ such that $a_{i} \in$ $A$ and $a_{j} \in A^{\prime}$ (i.e. we compute the distance between each pair of atoms of $A$ and $A^{\prime}$ ). A similar approach is applied to determine the distance between a ligand $L$ and an amino acid $A$. Distances greater than $7.0 \AA$ are not considered as 
we assume that there is no interaction between the atoms. Additionally, we define the class NextAminoAmino to represent the sort between each pair of amino acids in the chain.

After the object model of the protein is constructed, gsp4pdb-parser loads the data to the relational database system using a single bulk of SQL instructions. Next we describe the relational model used to store and manage the protein data.

\section{Protein data storage}

GSP4PDB uses a PostgreSQL database system (version 9.4) for storing and managing protein data obtained from the PDB repository. The current database contains information of 147,531 proteins (latest synchronization on February 1, 2019). The database is formed by the relational tables listed in Fig. 4.

The table "protein" contains general information about each protein. Information about the twenty standard amino acids, plus an "undefined" amino acid, is stored in the table "standard_amino". Most of the data rows in the database corresponds to the tables "distance_amino_amino" (distances between each pair of amino acids), "distance_ligand_amino" (distances between ligands and amino acids) and "next_amino_amino (sequential relationship between amino acids). Recall that the information of these tables is not provided (explicitly) by PDB, so it is computed during the pre-processing phase. The table protein_cath contains information about the CATH classification [24] of 114,593 proteins.
Figure 4 also shows the primary keys (attributes that identify rows in a table) and the foreign keys (attributes that refer a primary key in other table) in the database. Note that the attributes named "id" have been designed to describe data provenance. For instance, the atom_amino having id = "1B38_A_1_4" describes the atom number 4 , that belongs to the amino acid number 1 , of the chain " $\mathrm{A}$ ", in the protein "1B38".

Note that the database contains duplicated data in several tables (i.e. there is data redundancy). This denormalized design was selected in order to improve query computation and, consequently, to reduce the response time of the database system. The efficiency of the systems is also supported by the inclusion of $12 \mathrm{~B}$-tree indexes (indicated in Fig. 4 with the symbol $\Delta$ ), plus the unique indexes created automatically for primary keys. This is a stable configuration which we expect to improve in the future.

\section{Web user interface}

GSP4PDB includes an intuitive Web interface which allows to create a protein-ligand structural pattern, search the pattern in the relational database, and explore the search results using tabular and graphical representations. The web interface can be divided in three main components (see Fig. 5): the Navigator Bar, the Design Area and the Output Area.

The Navigation Bar allows to navigate among the main elements of the interface. This bar shows the number of database entries, and includes a button to display a "How

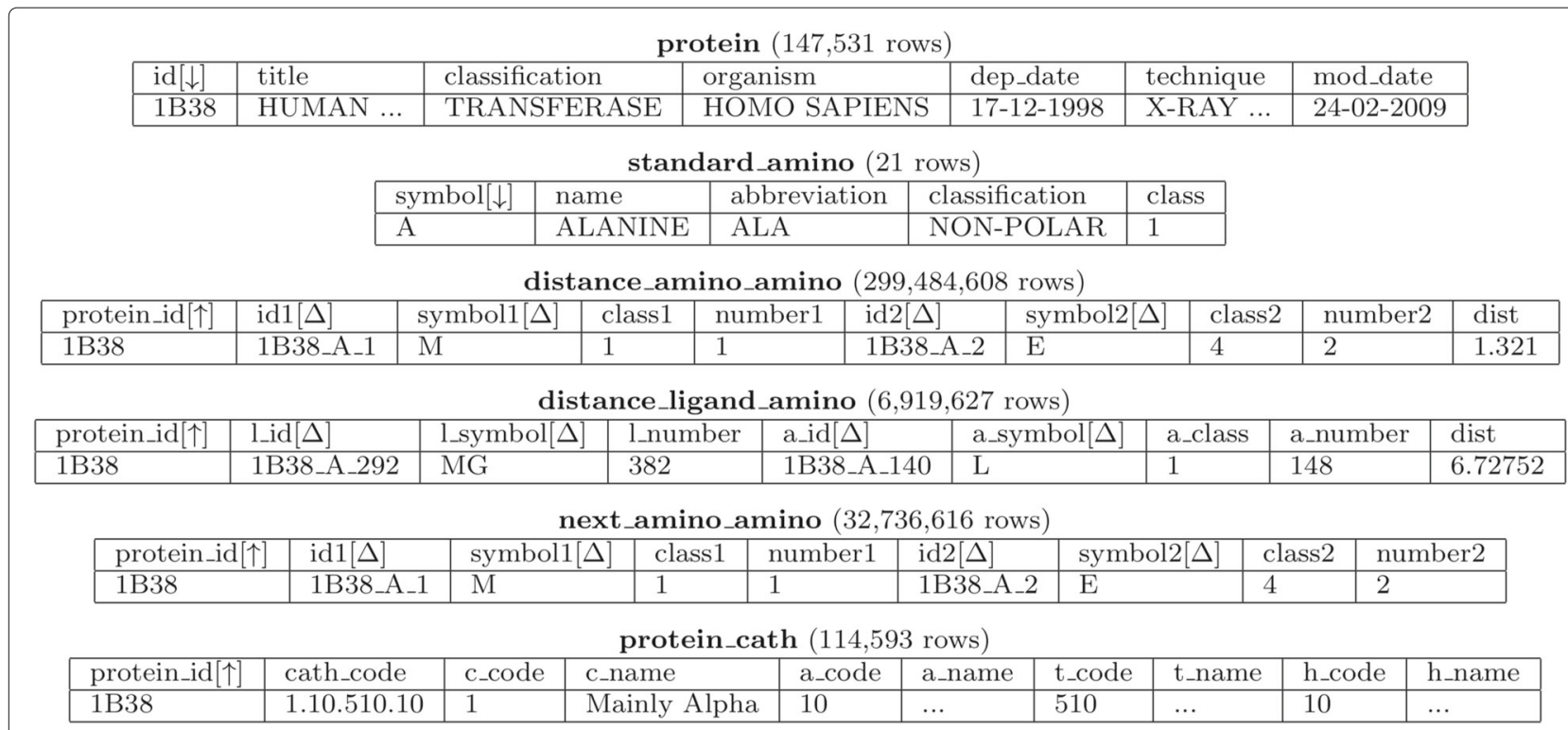

Fig. 4 Structure of the relational database used by GSP4PDB. For each table we show table's name, rows number, attribute and a sample data row. Primary keys and foreign keys are marked with $[\downarrow]$ and $[\uparrow]$ respectively. Indexed attributes are marked with $[\Delta]$ 


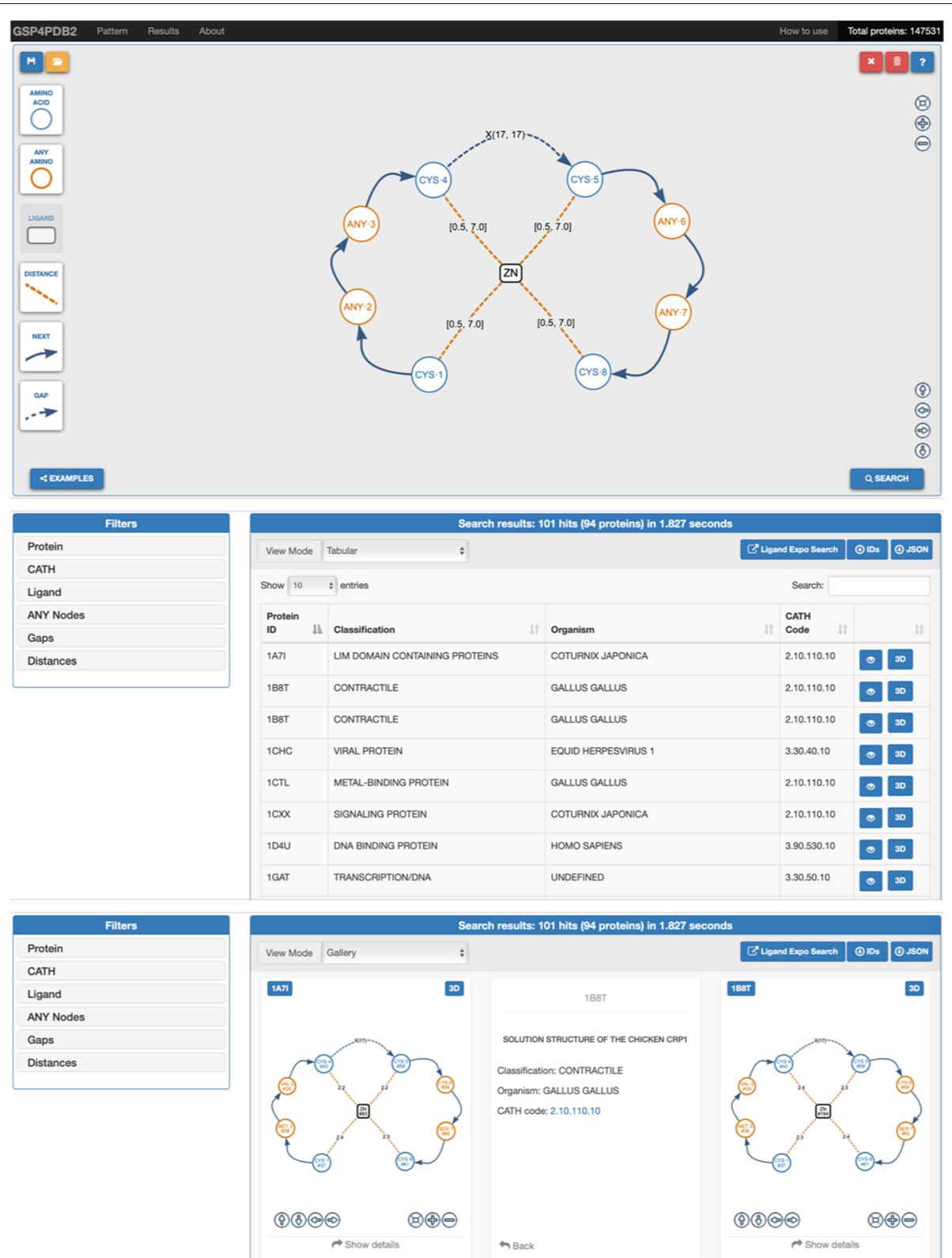

Fig. 5 Components of the GSP4PDB web interface: (Top) Navigation bar and Design area; (Middle) Output area in Tabular view mode; (Bottom) Output area in Gallery view mode

to use" popup containing a short description about the use of the tool.

The Design Area allows the user to "draw" a GSP by using drag-and-drop of buttons associated to the types of nodes and edges allowed in a GSP (the LIGAND button allows to create both ligand-nodes and any-ligand-nodes). On the right-hand side of the Design Area, there are buttons to move the pattern, delete elements, or clean the design space. There is also a "help" button which allows to display informative text (tooltips) over the buttons of the interface.
The Design Area shown in Fig. 5 contains a GSP which is equivalent to the one presented in Fig. 3. Each aminoacid-node is labeled with the 3-letter code of the corresponding amino acid, followed by its node identifier (e.g. CYS-1). Similarly, an any-amino-acid-node is labeled with the ANY prefix and the corresponding node identifier. Each distance-edge is represented as a dashed line and is labeled with a distance range (where [0.5,7.0] is the default assignment). Next-edges are represented as traditional arrows, and gap-edges are shown as dashed-arrows labeled with a gap range of the form $\mathrm{X}(\min , \max )$. The 
properties for nodes and edges can be changed by doing double-click on them.

Importantly any GSP can be saved and uploaded later again to allow the user to modify and optimize previous searches. In both cases, the GSP is managed as a JSON file having a special structure. In a similar way, the user is able to upload a GSP sample by clicking the "Examples" button. The Output Area shows the results of searching the GSP in the database, and provides filters that allow to further explore and analyse the results. The results can be viewed in Tabular or Gallery mode. Each row in the Tabular view mode shows information about a protein containing the pattern, a button to "see" more information about the solution (including a graph-based representation), and a "3D" button which allows to visualize the binding site in a JSmol popup.

In the Gallery view mode the solutions are shown as a collection of "cards". Each card contains the PDB ID of one matched protein, a graph-based representation of the binding site (similar to the input GSP), and a "Show details" button that flips the card to see additional information about the solution.

GSP4PDB includes a set of filters (or facets) that can be used to analyse the results. The filters are organized in six groups: "Protein" allows to filter the results by PDB ID, Classification and Organism; "CATH' includes filters to explore the CATH structural hierarchy (i.e. Class, Architecture, Topology/fold and Homologous superfamily) [25]; "Ligand" is active when an any-ligand node is used; "ANY Nodes", "Gaps" and "Distance" include a filter for each occurrence of an any-node, a gap-node or a next-edge. In order to support further off-line analysis, the user is also able to download the list of protein IDs or the solutions in their JSON encoding.

\section{From graph patterns to $S Q L$ queries}

Recall that GSP4PDB stores the protein data in a relational database (in this case, PostgreSQL). Hence, the simplest way to query the database is to use the SQL query language.

In this section we present a brief description of the method to transform a graph-based structural pattern into a SQL query expression. In general terms, the method generates a SQL query expression for each node-edgenode structure in the graph pattern. The final SQL query, expressing the complete graph pattern, is the compositions of all the sub-expressions.

The method defines transformations for the following node-edge-node structures:

- Ligand ... Distance ... Amino

- Ligand ... Distance ... ANY-amino

- ANY Ligand ... Distance ... Amino

- ANY Ligand ... Distance $\cdots$ ANY-Amino
- Amino - Distance - Amino

- Amino - Distance - ANY-amino

- ANY-amino - Distance - ANY-amino

- Amino - Next $\rightarrow$ Amino

- Amino - Next $\rightarrow$ ANY-amino

- ANYa-mino - Next $\rightarrow$ Amino

- ANY-amino - Next $\rightarrow$ ANY-amino

- Amino - Gap $\rightarrow$ Amino

- Amino - Gap $\rightarrow$ ANY-amino

- ANY-amino - Gap $\rightarrow$ Amino

- ANY-amino - Gap $\rightarrow$ ANY-amino

For instance, the SQL query corresponding to a Liganddistance-Amino structure (case 1) is the following:

SELECT

protein_id,

1_id, 1_number, 1_symbol,

a_id AS amino[amino_id]_id,

a_symbol AS amino[amino_id]_symbol,

a_number AS amino[amino_id_number,

dist AS min_ligand_amino[amino_id]

FROM

distance_ligand_amino

WHERE

1_symbol = '[ligand_code]' AND

a_symbol =' '[amino_code]' AND

(dist $>=$ [min_dist] AND dist $<=$ [max_dist])

The above SQL expression is a template for querying a distance relationship between a ligand and an amino acid. Note that the parameters of the template, represented as square brackets, should be replaced with values from the graph pattern in order to obtain the final SQL expression. For the sake of space, we do not present the rest of transformations. We refer the reader to the complete documentation of GSP4PDB which is available at https:// structuralbio.utalca.cl/gsp4pdb/.

\section{Results}

The utility of GSP4PDB was evaluated through the zinc finger domain. There are several groups for this domain that differ in the type of amino acids present in the pattern and the structural characteristics [12].

\section{Case study 1: visualization of structural patterns}

In order to evaluate GSP4PDB in terms of its features to design and visualize structural patterns, we have selected the Cys2His2 motif, a well-characterized class of zinc fingers which is related to a large number of regulatory proteins in mammals [14].

Figure 6 shows five patterns which were used to identify different Zinc Finger motifs in the Protein Data Bank. Pattern (a) shows a general GSP formed by two cysteines, two histidines, the zinc ligand, and four distance relations (all of them configured with a default range between 0.5 


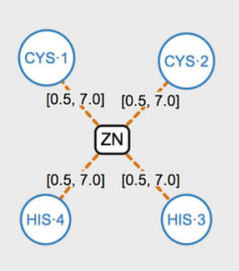

(a)

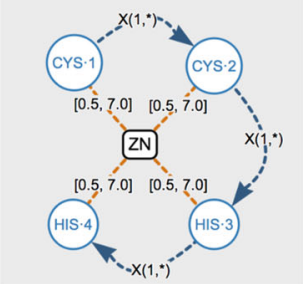

(b)

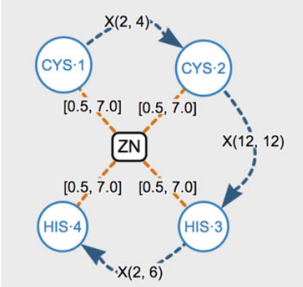

(c)

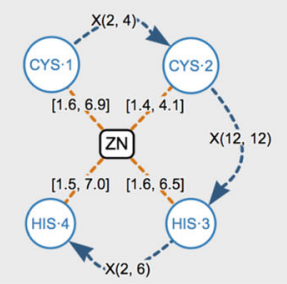

(d)

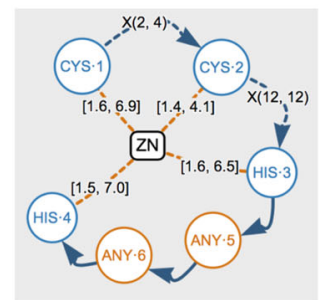

(e)

Fig. 6 Test patterns related to the Cys2His2 zinc finger. Search results: (a) 55,740 hits in 2,407 proteins; (b) 2,354 hits in 1,006 proteins; (c) and (d) 630 hits in 343 proteins; (e) 4 hits in 4 proteins

and 7.0 $)$. The search of pattern (a) results in 55,740 hits (occurrences), distributed in 2,407 proteins.

The large number of results in pattern (a) is due to the fact that no sequence order of the amino acids was given. Hence, for each result there will be several "mirror" results. This issue can be solved easily by including GAP edges, as they introduce a sequential restriction to the pattern. This is reflected in pattern (b), where the addition of three gap-edges reduces the number of hits to 2,354.

Note that all the gaps in pattern (b) have a range $\mathrm{X}\left(1,{ }^{*}\right)$, i.e. one or more amino acids in the gap. Following the results presented in [14], where the structure of the Cys2His2 zinc finger is described with the expression $\mathrm{CX}_{2-4} \mathrm{CX}_{12} \mathrm{HX}_{2-6} \mathrm{H}$, the general pattern can be restricted to the one shown in example (c). Recall that all the distance-edges were configured with the default range, i.e. $[0.5,7.0]$. In order to find the specific range for each distance, we can make use of filters. This allows us to define the ranges shown in example (d). Note that both patterns (c) and (d) have 630 hits. Finally, we can use anyamino-acid-nodes to search for specific sub-sequences inside a gap. For instance, assume we are interested in exploring subsequences of large 2 between the two histidines. This can be done by replacing the third gap by two any-amino-acid-nodes, as shown in example (e). The four results of this latest pattern can be further explored in a visual way or by using the corresponding filters. In both cases, we discovered that the subsequences ILE-ARG and LYS-ASP occur only once while GLU-ILE twice.

GSP4PDB filters allow to group results and calculate summarized data. Table 1 shows the sum of hits for specific groups of keywords found in the classification of the proteins containing the pattern (d). This summary shows that 9 results contain the keyword "ZINC FINGER" in their classification. It is important to note that as the classifications given in the PDB entry is often incomplete, any simple text search is not able to identify the majority of these Zinc fingers in the PDB. We expect to further optimize the pre-processing of the classification values in the future versions of GSP4PDB.
Importantly, GSP4PDB can be used to identify the functions of proteins that have not been annotated previously. Our analysis (Table 1) showed that there are 5 proteins in PDB having the Cys2His2 motif, and annotated with "Unknown Function" in their keyword property. There-

Table 1 Example of summarized data calculated over the results of the Cys2His2 pattern shown in Fig. $6 \mathrm{~d}$

\begin{tabular}{ll}
\hline Keywords & Hits \\
\hline TRANSCRIPTION (188) & 409
\end{tabular}

TRANSCRIPTION/DNA (185)

TRANSCRIPTION REGULATOR/DNA (14)

TRANSCRIPTION, METAL BINDING PROTEIN (2)

TRANSCRIPTION FACTOR/DNA (9)

TRANSCRIPTION REGULATION (7)

TRANSCRIPTION REGULATOR (2)

TRANSCRIPTION/RNA (2)

DNA BINDING PROTEIN (23)

DNA-BINDING PROTEIN (4)

DNA BINDING PROTEIN/DNA (79)

DNA BINDING PROTEIN/RNA/DNA (3)

METAL BINDING PROTEIN (21)

METAL BINDING PROTEIN/DNA (10)

DNA/METAL BINDING PROTEIN (3)

TRANSCRIPTION, METAL BINDING PROTEIN (2)

NUCLEAR PROTEIN/METAL BINDING PROTEIN (3)

TRANSFERASE (2)

TRANSFERASE/DNA (19)

GENE REGULATION (10)

GENE REGULATION/DNA (5)

ZINC FINGER (3)

ZINC FINGER DNA BINDING DOMAIN (6)

RNA BINDING PROTEIN (6)

RNA-BINDING PROTEIN/RNA (2)

RNA BINDING PROTEIN/RNA (1)

HYDROLASE/DNA (1)

HYDROLASE/DNA/RNA (5)

UNKNOWN FUNCTION

PROTEIN BINDING (2)

CELL CYCLE (2)

TRANSLATION REGULATOR (1)

TRANSLATION (1)

SPLICING (2)

LIGASE (1)

VIRUS (1)

\section{9}


fore, we could assume that if these proteins possess the domain of Zinc Finger, they are likely to be associated with DNA binding.

Recall that the GSP4PDB database contains CATH information as a complement to the data obtained from PDB. Table 2 shows information about the CATH classifications related to the Cys2His2 motif. For instance, there were 293 hits for the hierarchical level 3.30.160.60 corresponding to the "classical" Zinc finger motif.

GSP4PDB also facilitates the analysis of the interaction distances between the ligand and the different amino acids

Table 2 CATH information about the solutions of the Cys2His2 pattern shown in Fig. 6d

\begin{tabular}{|c|c|c|c|c|c|}
\hline Class & Architecture & $\begin{array}{l}\text { Topology/ } \\
\text { fold }\end{array}$ & $\begin{array}{l}\text { Homologous } \\
\text { superfamily }\end{array}$ & Hits & $\begin{array}{l}\text { CATH code } \\
\text { description }\end{array}$ \\
\hline 3 & - & - & - & 300 & Alpha Beta \\
\hline 3 & 30 & - & - & 300 & 2-Layer Sandwich \\
\hline 3 & 30 & 160 & - & 293 & $\begin{array}{l}\text { Double Stranded } \\
\text { RNA Binding } \\
\text { Domain }\end{array}$ \\
\hline 3 & 30 & 160 & 60 & 293 & $\begin{array}{l}\text { Classic Zinc } \\
\text { Finger }\end{array}$ \\
\hline 3 & 30 & 428 & - & 4 & $\begin{array}{l}\text { HIT family, } \\
\text { subunit A }\end{array}$ \\
\hline 3 & 30 & 428 & 10 & 4 & HIT-like \\
\hline 3 & 30 & 40 & - & 3 & Herpes Virus-1 \\
\hline 3 & 30 & 40 & 130 & 2 & Herpes Virus-1 \\
\hline 3 & 30 & 40 & 200 & 1 & Herpes Virus-1 \\
\hline 2 & - & - & - & 3 & Mainly Beta \\
\hline 2 & 170 & - & - & 1 & Beta Complex \\
\hline 2 & 170 & 270 & - & 1 & Beta-clip-like \\
\hline 2 & 170 & 270 & 10 & 1 & SET domain \\
\hline 2 & 60 & - & - & 1 & Sandwich \\
\hline 2 & 60 & 40 & - & 1 & $\begin{array}{l}\text { Immunoglobulin- } \\
\text { like }\end{array}$ \\
\hline 2 & 60 & 40 & 10 & 1 & Immunoglobulins \\
\hline 2 & 30 & - & - & 1 & Roll \\
\hline 2 & 30 & 170 & - & 1 & $\begin{array}{l}\text { Ribosomal } \\
\text { Protein L24e; } \\
\text { Chain: T; }\end{array}$ \\
\hline 2 & 30 & 170 & 10 & 1 & $\begin{array}{l}\text { Ribosomal } \\
\text { Protein L24e; } \\
\text { Chain: T; }\end{array}$ \\
\hline 1 & - & - & - & 1 & Mainly Alpha \\
\hline 1 & 10 & - & - & 1 & $\begin{array}{l}\text { Orthogonal } \\
\text { bundle }\end{array}$ \\
\hline 1 & 10 & 10 & - & 1 & $\begin{array}{l}\text { Arc Repressor } \\
\text { Mutant, subunit A }\end{array}$ \\
\hline 1 & 10 & 10 & 790 & 1 & $\begin{array}{l}\text { Arc Repressor } \\
\text { Mutant, subunit A }\end{array}$ \\
\hline \multicolumn{2}{|c|}{ No value No value } & No value & No value & 326 & \\
\hline
\end{tabular}

that make up the pattern, through the analysis of the data that are downloaded from the JSON file. An example of this is shown in Table 3 where the values of the average distances of the interactions between the $\mathrm{Zn}$ and the amino acids grouped by CATH code are shown.

This analysis clearly shows that class 2.30 .170 .10 , which corresponds to a ribosomal protein, is not a genuine $\mathrm{Zn} 2+$ binding as all distances are much larger than expected. If the user were interested in accurate average bond distances the search can easily be repeated with a smaller range such as distances between 1.5 and $3 \AA$.

\section{Case study 2: search of structural patterns}

In order to illustrate the use of GSP4PDB to represent and search different types of protein-ligand structural patterns, we selected six classes of zinc fingers $(\mathrm{C} 2 \mathrm{H} 2$ classical [14], C2H2 variation [26], THAP [27], C2HC [28], Fungal, CCHHC [29]). The corresponding graph-based structural patterns are shown in Fig. 7, and the results of their search are shown in Table 4.

Figure $7 \mathrm{a}$ shows a simple pattern that describes the structure of the classical Cys2His2 zinc finger [14]. A variation of this class is presented in Fig. 7b, where the any-amino-acid-node ANY.3 is used to represent a special sub-sequence between the amino acids CYS. 2 and HIS.4. Figure $7 \mathrm{c}$ shows a pattern containing a large-range gap-edge, i.e. $X(35,50)$. Similarly, the pattern shown in Fig. $7 \mathrm{~d}$ contains the gap-edge $\mathrm{X}\left(1,{ }^{*}\right)$ which defines an undefined range. Finally, the patterns shown in Fig. $7 \mathrm{e}$ and $f$ are examples of complex patterns containing multiple amino-acid-nodes, distance-edges, next-edges and gap-edges.

Table 4 contains the number of results obtained by searching the six examples described above. Note that each graphical representation maintains a clear similarity with its PROSITE textual representation.

Table 3 Average distances for the solutions of the Cys2His2 pattern shown in Fig. 6d

\begin{tabular}{|c|c|c|c|c|c|}
\hline \multirow[t]{2}{*}{ CATH code } & \multicolumn{4}{|c|}{ Average distance } & \multirow[t]{2}{*}{ Hits } \\
\hline & $C_{1}-Z n$ & $C_{2}-Z n$ & $\mathrm{H}_{1}-\mathrm{Zn}$ & $\mathrm{H}_{2}-\mathrm{Zn}$ & \\
\hline 3.30 .160 .60 & 2.32 & 2.28 & 2.09 & 2.12 & 293 \\
\hline 3.30 .428 .10 & 2.35 & 2.23 & 2.02 & 2.04 & 4 \\
\hline 3.30 .40 .130 & 2.13 & 2.13 & 1.99 & 6.96 & 2 \\
\hline 3.30 .40 .200 & 2.20 & 2.38 & 2.10 & 2.18 & 1 \\
\hline 2.170 .270 .10 & 2.29 & 2.28 & 2.12 & 2.12 & 1 \\
\hline 2.60 .40 .10 & 2.61 & 2.51 & 2.39 & 2.41 & 1 \\
\hline 2.30 .170 .10 & 4.39 & 4.01 & 5.11 & 6.49 & 1 \\
\hline 1.10 .10 .790 & 2.52 & 2.66 & 2.36 & 2.38 & 1 \\
\hline No value & 2.33 & 2.25 & 2.07 & 2.08 & 326 \\
\hline
\end{tabular}

This table shows the average distances for interactions between ligand $\mathrm{Zn}$ and the amino acids ( $\mathrm{Cys}_{1}, \mathrm{Cys}_{2}, \mathrm{His}_{1}$ and $\left.\mathrm{His}_{2}\right)$, grouped by $\mathrm{CATH}$ code 


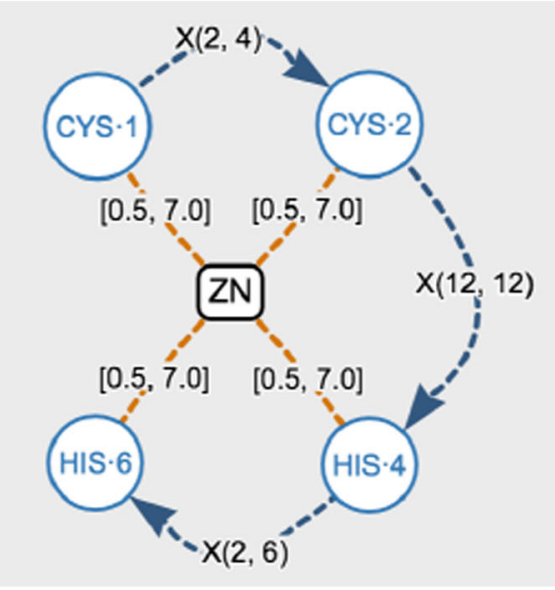

(a) $\mathrm{C} 2 \mathrm{H} 2$-type (Classical)

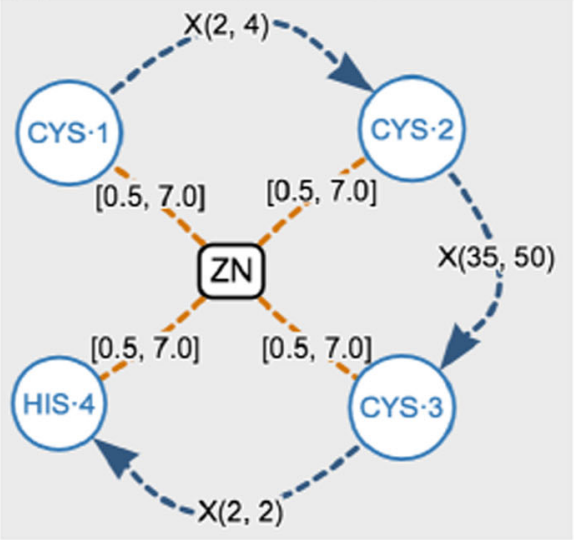

(c) THAP-type

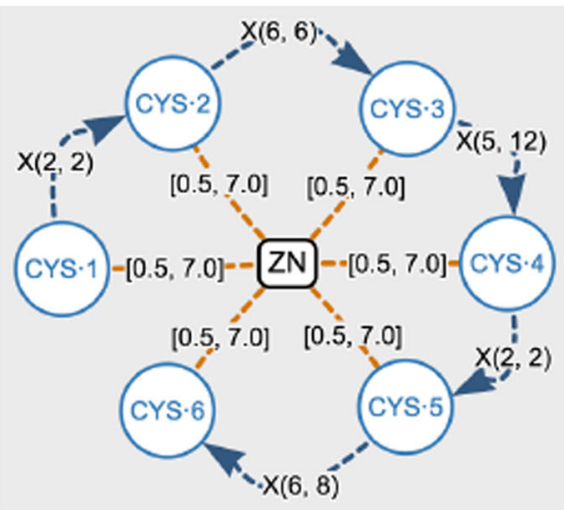

(e) Fungal-type

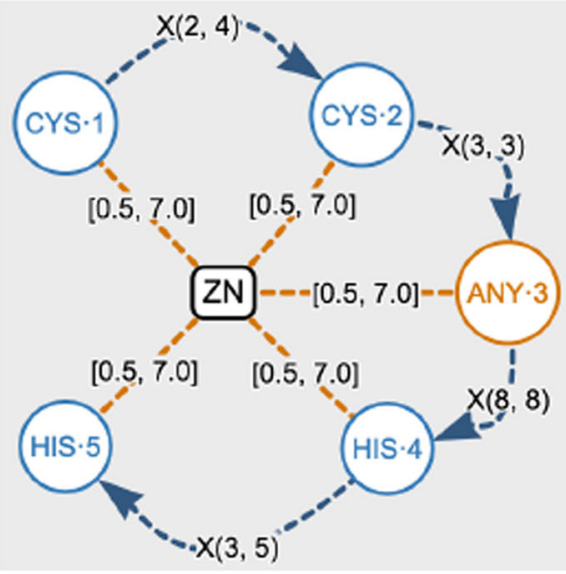

(b) $\mathrm{C} 2 \mathrm{H} 2$-type (Variation)

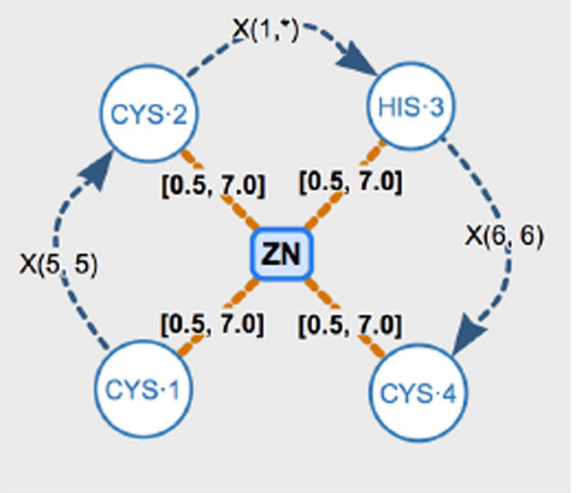

(d) C2HC-type

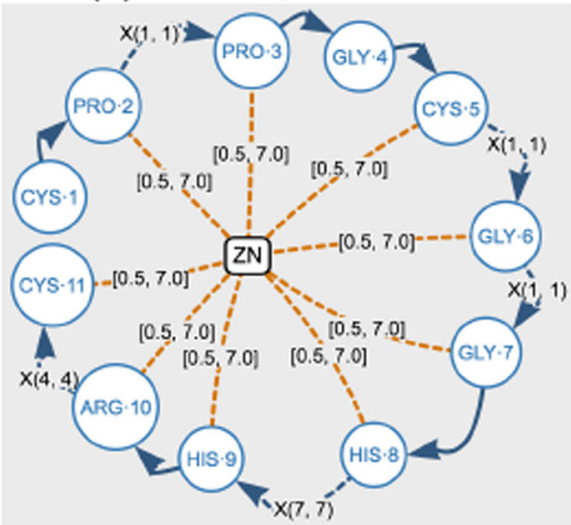

(f) CCHHC-type

Fig. 7 Graph-based structural patterns for six classes of zinc fingers

This case study illustrates how starting from a very general search of $\mathrm{Zn} 2+$ binding sites with a certain sequence pattern different classes of Zinc-fingers can be identified in the entire PDB.

\section{Case study 3: exploration of structural patterns}

Data exploration is about efficiently extracting knowledge from data even if we do not know exactly what we are looking for [30]. It usually implies to use visual exploration to understand what is in a dataset and the characteristics of the data. These characteristics can include size or amount of data, completeness of the data, correctness of the data, possible relationships amongst data elements, etc.

We used GSP4PDB to conduct a data exploration experiment to discover sub-patterns for a given pattern. In this 
Table 4 Six classes of zinc fingers used in case study $2(\mathrm{C} 2 \mathrm{H} 2$ classical, $\mathrm{C} 2 \mathrm{H} 2$ variation, THAP, C2HC, Fungal, CCHHC)

\begin{tabular}{|c|c|c|c|}
\hline Zinc Class & Textual Pattern (PROSITE convention) & Hits & Time (s) \\
\hline $\mathrm{C} 2 \mathrm{H} 2-\mathrm{C}$ & $C-x(2,4)-C-x(12)-H-x(2,6)-H$ & 630 & 1.72 \\
\hline $\mathrm{C} 2 \mathrm{H} 2-\mathrm{v}$ & $C-x(2,4)-C-x(3)-[L I V M F Y W C]-x(8)-H-x(3,5)-H$ & 554 & 2.89 \\
\hline THAP & $C-x(2,4)-C-x(35,50)-C-x(2)-H$ & 36 & 1.64 \\
\hline $\mathrm{C} 2 \mathrm{HC}$ & $C-x(5)-C-x(n)-H-x(6)-C$ & 6 & 0.83 \\
\hline Fungal & $C-x(2)-C-x(6)-C-x(5,12)-C-x(2)-C-x(6,8)-C$ & 28 & 0.87 \\
\hline $\mathrm{CCHHC}$ & $C-P-x(1)-P-G-C-x(1)-G-x(1)-G-H-x(7)-H-R-x(4)-C$ & 1 & 1.14 \\
\hline
\end{tabular}

For each pattern we present the number of results (hits) and the computation time (in seconds)

case, we selected as target the Cys2His2 classical zinc finger, whose pattern is shown in Fig. 7a. Table 5 shows the exploration results.

By using the filters of GSP4PDB, we were able to identify nine sub-patterns. Each sub-pattern is given by the specific sizes of the gaps (G1, G2, G3) defined by the main graph pattern. For instance, the first sub-pattern describes the structure $\mathrm{C}-\mathrm{X}(2)-\mathrm{C}-\mathrm{X}(12)-\mathrm{H}-\mathrm{X}(2)-\mathrm{H}$. For each pattern, we group and show the number of PDBs, classifications, organisms, CATH codes and average distances. A number in parentheses is used to indicate the number of results for each specific value ("?" denotes an undefined value).

This structural bioinformatic search can be utilized as a starting point for further functional analysis of the subgroups identified.

\section{Discussion}

In this section we review related approaches, discuss the general use of graph theory in bioinformatics and discuss the advantages of the software presented here.

\section{Related work}

We reviewed several tools related to visualize protein structures. Due to space restrictions we just mention a small number of tools and system. The following articles present reviews and comparisons of visualization tools: [31-33].

There are tools like JSMol [34], 3DMol [35], JSME [36], LigPlot+ [37], NGL [38] and ChemDoodle [39] which are oriented to visualize and edit molecular structures. These tools provide libraries for protein visualization which are used by databases and systems related to protein-ligand interactions. Among them we can mention Ligand Search (RCSB PDB), PDBbind [40], PDBSum [31], PubChem [41], AutoDock [42], iview [43], PDB-Ligand [44], Proteopedia [45] and sc-PDB [46]. In addition, there are a number of specialised graphical user interfaces designed for specific goals. For instance, PoseView [47] provides a special 2D diagram to visualize molecular interaction patterns, and GIANT [48] provides a 3D viewer based on density maps.
Figure 8 shows five types of graphical representations used to visualize distinct aspects of a protein's structure. The molecular structure is usually represented by using a 2D schematic representation (Fig. 8a). The primary structure is visualized using chain-oriented representations (e.g. "wiring" diagrams), 2D charts (Fig. 8b) and 3D charts (Fig. 8c). A three-dimensional representation can use different types of shapes: lines, sticks, balls, spheres and surfaces (Fig. 8d). The secondary structure is also visualized in 3D, but using shapes like folds, strands, cylinders and plates (Fig 8e). The tertiary and quaternary structures are usually represented as a combination of $2 \mathrm{D}$ and $3 \mathrm{D}$ representations.

Our search and analysis of the related tools and systems, allowed us to verify that the graph-based representation of GSP4PDB is a novel approach. However, it is important to mention that most of the current approaches for visualizing protein structures share a common foundation: a graph-based structure.

In terms of interfaces for searching protein-ligand interactions, there are four basic types: form-based, textbased, sequence-based and molecular-based. A formbased interface [49] consists of a web form where the user is able to input different parameters (e.g. PDB code, protein name, ligand name, and so on) to conduct the search. In a text-based interface [40] a query is introduced as a textual representation (e.g. SMILES) of the protein-ligand interaction. A sequence-based interface [40] requires a textual representation (e.g. FASTA) of the protein sequence to conduct the search. A molecularbased interface [50] extends the schematic representation of a protein with complex conditional expressions for atoms and bonds. Most applications combine the above approaches to form a complex but multi-functional query and analysis interface.

In contrast to the current approaches, the graphbased query interface provided by GSP4PDB allows the user to create different types of structural patterns in a simple way (by doing drag-and-drop). Note that the notions of any-amino and any-ligand allows to explore and discover new kinds of structural patterns.

\section{Why a graph-based representation?}

Graphs are omnipresent in our lives and have been increasingly used in a variety of application domains. In our context, graphs are a natural way of representing biological networks, and graph theoretical concepts are useful for the description and analysis of interactions and relationships in biological systems [51].

Different classes of graphs can be used to model different levels of abstraction and knowledge. For example, graphs have been used to represent protein-protein interaction networks [32] and cellular processes [52]. It is 
Table 5 Summary of the results of case study 3: Sub-patterns of the Cys2His2 zinc finger

\begin{tabular}{|c|c|c|c|c|c|c|c|c|c|c|c|c|c|}
\hline \multicolumn{3}{|c|}{ Gap } & \multicolumn{3}{|c|}{ Protein } & \multicolumn{4}{|c|}{ Cath Code ( $0=$ No value) } & \multicolumn{4}{|c|}{ AVG Distance } \\
\hline G1 & G2 & G3 & PDBs & Classification & Organism & C & A & $\mathrm{T}$ & $\mathrm{H}$ & ZN-Cys1 & ZN-Cys2 & ZN-His1 & $\mathrm{ZN}-\mathrm{His} 2$ \\
\hline 2 & 12 & 2 & 4 & $\begin{array}{l}\text { TRANSCRIPTION (1), } \\
\text { METAL BINDING } \\
\text { PROTEIN/DNA (1), } \\
\text { TRANSCRIPTION/DNA(1), } \\
\ldots\end{array}$ & HOMO SAPIENS (4) & $\begin{array}{l}0(2) \\
3(1) \\
3(1)\end{array}$ & $\begin{array}{l}0(2) \\
30(1) \\
30(1)\end{array}$ & $\begin{array}{l}0(2) \\
40(1) \\
160(1)\end{array}$ & $\begin{array}{l}0(2) \\
200(1) \\
60(1)\end{array}$ & 2.25 & 2.31 & 2.07 & 5.49 \\
\hline 2 & 12 & 3 & 4 & $\begin{array}{l}\text { TRANSCRIPTION (139), } \\
\text { TRANSCRIPTION/DNA (91), } \\
\text { GENE REGULATION/DNA (10), } \\
\text { UNKNOWN FUNCTION (5), } \\
\text {... }\end{array}$ & $\begin{array}{l}\text { HOMO SAPIENS (261), } \\
\text { UNDEFINED (50), } \\
\text { MUS MUSCULUS (40), } \\
\text { MUS (10), } \\
\ldots\end{array}$ & $\begin{array}{l}0(198) \\
2(1) \\
3(172) \\
3(4)\end{array}$ & $\begin{array}{l}0(198) \\
60(1) \\
30(172) \\
30(4)\end{array}$ & $\begin{array}{l}0(198) \\
40(1) \\
160(172) \\
428(4)\end{array}$ & $\begin{array}{l}0(198) \\
10(1) \\
60(172) \\
10(4)\end{array}$ & 2.33 & 2.26 & 2.08 & 2.07 \\
\hline 2 & 12 & 4 & 97 & $\begin{array}{l}\text { TRANSCRIPTION (29), } \\
\text { TRANSCRIPTION/DNA (22), } \\
\text { METAL BINDING PROTEIN (7), } \\
\ldots\end{array}$ & $\begin{array}{l}\text { MUS MUSCULUS (6), } \\
\text { HOMO SAPIENS (70), } \\
\text { UNDEFINED (11), } \\
\ldots\end{array}$ & $\begin{array}{l}0(66) \\
2(1) \\
3(30)\end{array}$ & $\begin{array}{l}0(66) \\
170(1) \\
30(30)\end{array}$ & $\begin{array}{l}0(66) \\
270(1) \\
160(30)\end{array}$ & $\begin{array}{l}0(66) \\
10(1) \\
60(30)\end{array}$ & 2.30 & 2.24 & 2.05 & 2.05 \\
\hline 2 & 12 & 5 & 15 & $\begin{array}{l}\text { TRANSCRIPTION (15), } \\
\text { RNA BINDING } \\
\text { PROTEIN RNA (1), } \\
\ldots\end{array}$ & $\begin{array}{l}\text { HOMO SAPIENS (9), } \\
\text { MUS MUSCULUS (1), } \\
\text { XENOPUS LAEVIS (2), } \\
\ldots\end{array}$ & $\begin{array}{l}0(4) \\
1(1) \\
3(10)\end{array}$ & $\begin{array}{l}0(4) \\
10(1) \\
30(10)\end{array}$ & $\begin{array}{l}0(4) \\
10(1) \\
160(10)\end{array}$ & $\begin{array}{l}0(4) \\
790(1) \\
60(10)\end{array}$ & 2.32 & 2.29 & 2.37 & 2.60 \\
\hline 3 & 12 & 4 & 1 & METAL BINDING PROTEIN (1) & HOMO SAPIENS (1) & $0(1)$ & $0(1)$ & $0(1)$ & $0(1)$ & 6.00 & 1.72 & 1.94 & 2.32 \\
\hline 3 & 12 & 5 & 2 & $\begin{array}{l}\text { RNA BINDING PROTEIN (69), } \\
\text { METAL BINDING PROTEIN (1) }\end{array}$ & $\begin{array}{l}\text { XENOPUS LAEVIS (1), } \\
\text { SYNECHOCOCCUS } \\
\text { ELONGATUS (1) }\end{array}$ & $\begin{array}{l}2(1) \\
3(1)\end{array}$ & $\begin{array}{l}30(1) \\
30(1)\end{array}$ & $\begin{array}{l}170(1) \\
160(1)\end{array}$ & $\begin{array}{l}10(1) \\
60(1)\end{array}$ & 5.60 & 3.15 & 3.60 & 4.29 \\
\hline 4 & 12 & 3 & 117 & $\begin{array}{l}\text { TRANSCRIPTION DNA (69), } \\
\text { TRANSCRIPTION } \\
\text { FACTOR/DNA (6), } \\
\ldots\end{array}$ & $\begin{array}{l}\text { HOMO SAPIENS (63), } \\
\text { MUS MUSCULUS (19), } \\
\text { ESCHERICHIA COLI (2), } \\
\ldots\end{array}$ & $\begin{array}{l}0(42) \\
3(75)\end{array}$ & $\begin{array}{l}0(42) \\
30(75)\end{array}$ & $\begin{array}{l}0(42) \\
160(75)\end{array}$ & $\begin{array}{l}0(42) \\
60(75)\end{array}$ & 2.28 & 2.30 & 2.07 & 2.04 \\
\hline 4 & 12 & 4 & 8 & $\begin{array}{l}\text { METAL BINDING PROTEIN (1), } \\
\text { PROTEIN BINDING (1), } \\
\text { DNA BINDING PROTEIN (2), } \\
\ldots\end{array}$ & $\begin{array}{l}\text { HOMO SAPIENS (3), } \\
\text { ARABIDOPSIS } \\
\text { THALIANA (1), } \\
\ldots\end{array}$ & $\begin{array}{l}0(4) \\
3(4)\end{array}$ & $\begin{array}{l}0(4) \\
30(4)\end{array}$ & $\begin{array}{l}0(4) \\
160(4)\end{array}$ & $\begin{array}{l}0(4) \\
60(4)\end{array}$ & 2.26 & 2.26 & 2.07 & 2.14 \\
\hline 4 & 12 & 6 & 2 & $\begin{array}{l}\text { TRANSLATION } \\
\text { REGULATOR (1), } \\
\text { METAL BINDING PROTEIN (1) }\end{array}$ & HOMO SAPIENS (2) & $3(2)$ & $30(2)$ & $40(2)$ & $130(2)$ & 2.13 & 2.13 & 1.99 & 6.95 \\
\hline & & & 630 & & & & & & & 2.33 & 2.26 & 2.08 & 2.12 \\
\hline
\end{tabular}

Each row contains information of a sub-pattern, where G1, G2 and G3 indicate the specific sizes for the gaps of the pattern shown in Fig. 7a. For instance, the textual representation of the first sub-pattern is $\mathrm{C}-\mathrm{X}(2)-\mathrm{C}-\mathrm{X}(12)-\mathrm{H}-\mathrm{X}(2)-\mathrm{H}$

important to highlight that the graph-based model introduced in this article can be easily extended to support more complex protein structural patterns (e.g. patterns containing multiple ligands).

Protein data modeled as graphs is been supported by the development of graph database systems. These systems enable efficient storage and processing of the encoded biological relationships, and can offer great speedups over relational databases [53]. For instance, the Neo4j graph database (and its query language, Cypher) has been used for mining protein graphs [54], and to perform complex queries over biological pathway databases [55].

\section{Key features of gSP4PDB}

Next we discuss the advantages of GSP4PDB in terms of the following features: multi-purpose, usability, efficiency, availability, maintainability, interoperability and multi-Platform. 


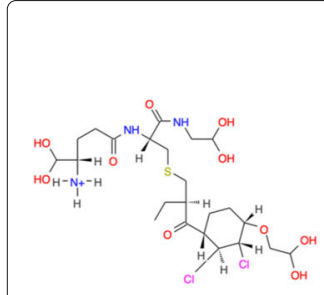

(a)

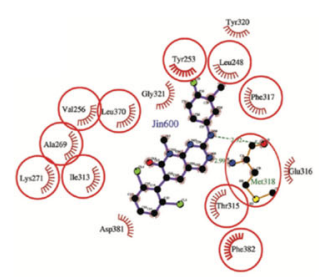

(b)

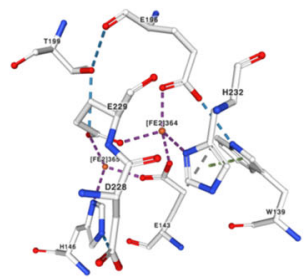

(c)

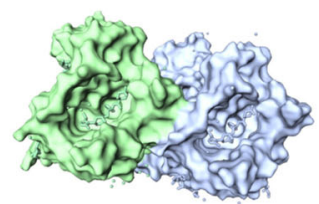

(d)

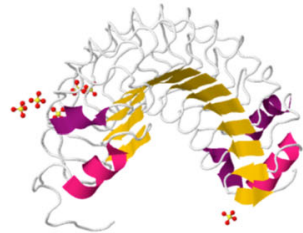

(e)

Fig. 8 Types of charts used in protein structure visualization: (a) Molecular structure represented in JSME; (b) Interaction diagram used by LigPlot+; (c) Ball \& Stick visualization provided by NGL (WebGL); (d) Surface representation supported by iview; (e) Cartoon visualization provided by JSmol

Multi-purpose GSP4PDB allows the visualization, search and exploration of common structural patterns in protein-ligand interactions. Additionally, it facilitates the discovery of complex patterns that could be linked to the use or interaction with drugs or molecules of biotechnological interest. This information can be particularly important in the area of protein design and the creation of new enzymes.

Usability GSP4PDB provides a very simple and intuitive graph-based visual interface to represent a protein-ligand interaction. As discussed before, a graph is a powerful abstraction to represent the relationships between biological entities. The usability of GSP4PDB was evaluated by researchers and students of the bioinformatics department at Universidad de Talca (Chile).

Efficiency GSP4PDB allows fast and massive search of the structural characteristics in all the PDB data base facilitating the mining of data in three-dimensional information, something that is complex and expensive to do by traditional methods. The efficiency of the systems is given by the denormalized design of the database and the use of indexes. We believe that the efficiency could be improved with the use of a graph database system (instead of the current PostgreSQL relational database).

Availability GSP4PDB is hosted in a Lightsail virtual private server of Amazon Web Services (AWS). Hence, the system inherits AWS features like reliability, highperformance, persistent SSD-based block storage, load balancing, data protection and network stability.

Maintainability The installation of GSP4PDB in a web server is very simple and does not have special requirements. The most costly step (in terms of time) is the creation of the database due to the pre-processing of the entire PDB dataset. After the first data loading stage, the updating process is very simple thanks to the features of gsp4pdb-parser.
Interoperability A protein-ligand pattern can be stored as a JSON file, and can be loaded in the future. The results are shown by using either a traditional tabular representation or a graphical mode view (following a graph-based representation). The results can be exported as a text file with the list of protein IDs, or as a structured JSON file containing the encoding of the graph-based representation of each solution.

Multi-platform GSP4PDB is distributed as a web application and has been tested in all current browsers (see the section about Availability and requirements). The system does not require special plugins in the front-end, although requires PostgreSQL database system in the back-end.

\section{Conclusions}

This paper presents GSP4PDB, a novel tool which allows to search protein-ligand interactions by using a simple and intuitive graphical representation based on graphs. Here, we describe the design and implementation of the three main elements, pre-processing, data storage and web interfaces. Furthermore, our case studies on the Zinc finger motifs demonstrate how new functionalities can be discovered for proteins with hitherto unknown function.

As future work we expect to extend the notion of protein-ligand structural patterns to support filters and advanced relationships (e.g. metal interaction geometries). Additionally, we will explore the use of big data technologies for storing and query PDB data. Particularly, we expect to use graph-based technologies like Giraph, a graph processing framework built on top of Apache Hadoop.

\section{Availability and requirements Project name: GSP4PDB \\ Project home page: http://gdblab.com/gsp4pdb/ gsp4pdb2/}

Hardware (host): Lightsail virtual private server, 2 Core Processor, 8 GB Memory, 160 GB SSD Disk, 5 TB Transfer Operating system(s): Platform independent (Web)

Programming language: $\mathrm{PHP}$

Compatible Web navigators: Chrome 71.0.3578.98, 


\section{Internet Explorer 11, Opera 58.0.3135.47, Firefox 64.0.2 , Safari 12.0.2 License: Academic Free License (AFL)}

\section{Abbreviations}

ATP: Adenosine triphosphate; AWS: Amazon web services; DNA: Deoxyribonucleic acid; ID: Identifier; GSP: Graph-based structural pattern; PDB: Protein data bank; SMILES: Simplified molecular input line entry specification

\section{Acknowledgments}

The first version of GSP4PDB was created by Diego Cisterna, as part of his final engineering project at Universidad de Talca (Chile)

\section{About this supplement}

This article has been published as part of BMC Bioinformatics Volume 21 Supplement 2, 2020: Selected articles from the 6th International Work-Conference on Bioinformatics and Biomedical Engineering. The full contents of the supplement are available online at URL.

\section{Authors' contributions}

RA led the collaborative work, the software design and development, functionality test and manuscript writing. MA participated in software design, proposed the user's needs, functionality test and manuscript writing. RG participated in software development and the functionality test. JAR participated in software design and the manuscript writing. EP participated in the functionality test and the manuscript writing. All authors read and approved the final manuscript.

\section{Funding}

R. Angles was supported by the Millennium Institute for Foundational Research on Data. M. Arenas was supported by the Comisión Nacional de Investigación Científica y Tecnológica (under Grant FONDECYT de Iniciación 11180665), and by the Regional Government of Maule (under FIC-R Project BIP 40.001.111-0). R. García was supported by the Enlace-Fondecyt Project "Graph database models for computational protein design" (Universidad de Talca). Publication costs are funded by the Universidad de Talca and the Durham University.

\section{Availability of data and materials}

The datasets used and/or analyzed during the current study are available from the corresponding author on reasonable request and the PDB database.

\section{Ethics approval and consent to participate}

Not applicable.

\section{Consent for publication}

Not applicable.

\section{Competing interests}

The authors declare that they have no competing interests.

\section{Author details}

${ }^{1}$ Department of Computer Science, Universidad de Talca, Camino Los Niches $\mathrm{Km} \mathrm{1}$, Curicó, Chile. ${ }^{2}$ Millennium Institute for Foundational Research on Data, Santiago, Chile. ${ }^{3}$ Centro de Bioinformática y Simulación Molecular, Universidad de Talca, Talca, Chile. ${ }^{4}$ Faculty of Engineering, Universidad de Talca, Camino Los Niches Km 1, Curicó, Chile. ${ }^{5}$ Department of Chemistry, Durham University, Durham, DH1 3LE, United Kingdom. ${ }^{6}$ Department of Biosciences, Durham University, Durham, DH1 3LE, United Kingdom.

\section{Published: 13 March 2020}

\section{References}

1. Ehrt C, Brinkjost $T$, Koch O. Impact of binding site comparisons on medicinal chemistry and rational molecular design. J Med Chem. 2016:59(9):4121-51.

2. Meysman P, Zhou C, Cule B, Goethals B, Laukens K. Mining the entire protein databank for frequent spatially cohesive amino acid patterns. BioData Min. 2015;8(4): https://doi.org/10.1186/s13040-015-0038-4.

3. Bruce D, Cardew EM, Freitag-Pohl S, E P. How to stabilize your protein: stability screens for thermal shift assays and nano Differential Scanning
Calorimetry in the Virus-X project. J Visualized Exp. 2019;In press:. https:// doi.org/10.3791/58666.

4. Williams MA. Protein-Ligand Interactions: Fundamentals. New York: Humana Press; 2013, pp. 3-34.

5. Konc J, Janezic D. Binding site comparison for function prediction and pharmaceutical discovery. Curr Opin Struct Biol. 2014;25:34-9.

6. Mavromoustakos T, Durdagi S, Koukoulitsa C, Simcic M, Papadopoulos MG, Hodoscek M, Golic Grdadolnik S. Strategies in the rational drug design. Curr Med Chem. 2011;18(17):2517-30.

7. Wang T, Wu M-B, Zhang R-H, Chen Z-J, Hua C, Lin J-P, Yang L-R. Advances in computational structure-based drug design and application in drug discovery. Curr Top Med Chem. 2016;16(9):901-16.

8. Tatum NJ, Liebeschuetz JW, Cole JC, Frita R, Herledan A, Baulard AR Willand N, Pohl E. New active leads for tuberculosis booster drugs by structure-based drug discovery. Org Biomol Chem. 2017;15:10245-55.

9. Hol WGJ. Three-dimensional structures in the design of therapeutics targeting parasitic protozoa: reflections on the past, present and future. Acta Crystallogr F Struct Biol Commun. 2015;71:485-99.

10. Cassandri M, Smirnov A, Novelli F, Pitolli C, Agostini M, Malewicz M, Melino G, Raschellà G. Zinc-finger proteins in health and disease. Cell Death Discov. 2017;3(17071):1-12

11. Eom KS, Cheong JS, Lee SJ. Structural analyses of zinc finger domains for specific interactions with dna. J Microbiol Biotechnol. 12:2019-29. https:// doi.org/10.4014/jmb.1609.09021.

12. Krishna SS, Majumdar I, Grishin NV. Structural classification of zinc fingers: Survey and Summary. Nucleic Acids Res. 2003;31:532-50.

13. The PA line notation. https://prosite.expasy.org/prosuser.html. Accessed 24 Apr 2019.

14. Iuchi S. Three classes of $\mathrm{c} 2 \mathrm{~h} 2$ zinc finger proteins. Cell Mol Life Sci. 2001;58(4):625-35.

15. Berg JM. Zinc fingers and other metal-binding domains. J Biol Chem. 1990;265(12):6513-6.

16. Berman HM, Westbrook J, Feng Z, Gilliland G, Bhat TN, Weissig H, Shindyalov IN, Bourne PE. The Protein Data Bank. Nucleic Acids Res. 2000;28(1):235-42.

17. Lesk A. Introduction to Protein Science: Architecture, Function, and Genomics, 2nd edn. UK: Oxford University Press; 2010.

18. Berg JM, Tymoczko JL, Stryer L. Protein Structure and Function, Biochemistry, 5th edn. New York: W. H. Freeman; 2002.

19. Branden C, Tooze J. Introduction to Protein Structure, 2nd edn. USA: Garland Science; 1998.

20. Zinc finger $\mathrm{C} 2 \mathrm{H} 2$-type domain signature and profile. https://prosite. expasy.org/PDOC00028. Accessed 24 Apr 2019.

21. Zheng R, Blobel GA. Gata transcription factors and cancer. Genes Cancer. 2010;1(12):1178-88

22. GATA-type zinc finger domain signature and profile. https://prosite. expasy.org/PDOC00300. Accessed 24 Apr 2019

23. BIOJAVA - The open-source java framework for bioinformatics. https:// biojava.org/. Accessed 24 Apr 2019.

24. CATH-Gene3D. http://www.cathdb.info/. Accessed 24 Apr 2019.

25. Pearl FMG, Bennett CF, Bray JE, Harrison AP, Martin N, Shepherd A, Sillitoe I, Thornton J, Orengo CA. The CATH database: an extended protein family resource for structural and functional genomics. Nucleic Acids Res. 2003;31(1):452-5.

26. Zinc finger $\mathrm{C} 2 \mathrm{H} 2$ type domain signature. https://prosite.expasy.org/ PS00028. Accessed 24 Apr 2019

27. Zinc finger THAP-type profile. https://prosite.expasy.org/PDOC50950. Accessed 24 Apr 2019.

28. Zinc finger $\mathrm{C} 2 \mathrm{HC}$ baculovirus (BV)-type profile. https://prosite.expasy.org/ PDOC51807. Accessed 24 Apr 2019.

29. Zinc finger CCHHC-type profile. https://prosite.expasy.org/doc/PS51802 Accessed 24 Apr 2019

30. Idreos S, Papaemmanouil O, Chaudhuri S. Overview of Data Exploration Techniques: 2015. https://doi.org/10.1145/2723372.2731084.

31. Laskowski RA, Pravda L, Vařeková RS, Thornton JM. Pdbsum: Structural summaries of pdb entries. Protein Sci. 2017;27(1):129-34.

32. Friedrich C, Schreiber F. Visualisation and navigation methods for typed protein-protein interaction networks. Appl Bioinforma. 2003;2(3 Suppl): 19-24.

33. Jeanquartier F, Jean-Quartier C, Holzinger A. Integrated web visualizations for protein-protein interaction databases. BMC Bioinformatics. 2015;16(195):. https://doi.org/10.1186/s12859-015-0615-z. 
34. Hanson RM, Prilusky J, Renjian Z, Nakane T, Sussman JL. JSmol and the Next-Generation Web-Based Representation of 3D Molecular Structure as Applied to Proteopedia. Isr J Chem. 2013;53(3-4):207-16.

35. Koes D, Rego N. 3Dmol.js: molecular visualization with WebGL. Bioinformatics. 2014;31(8):1322-4.

36. Bienfait B, Ertl P. JSME: a free molecule editor in JavaScript. J Cheminformatics. 2013;5(24): https://doi.org/10.1186/1758-2946-5-24.

37. Laskowski RA, Swindells MB. LigPlot+: multiple ligand-protein interaction diagrams for drug discovery. J Chem Inf Model. 2011;51(10):2778-86.

38. Prlić A, Bradley AR, Duarte JM, Rose PW, Rose AS, Valasatava Y. NGL viewer: web-based molecular graphics for large complexes. Bioinformatics. 2018;34(21):3755-8.

39. Burger MC. ChemDoodle Web Components: HTML 5 toolkit for chemical graphics, interfaces, and informatics. J Cheminformatics. 2015;7(35): https://doi.org/10.1186/s13321-015-0085-3.

40. Li J, Liu J, Han L, Wang R, Nie W, Li Y, Liu Y, Liu Z, Zhao Z. PDB-wide collection of binding data: current status of the PDBbind database. Bioinformatics. 2014;31(3):405-12.

41. Gindulyte A, Shoemaker BA, Yu B, He J, Zhang J, Chen J, Zaslavsky L, Thiessen PA, Li Q, He S, Kim S, Cheng T, Bolton EE. PubChem 2019 update: improved access to chemical data. Nucleic Acids Res. 2018:47(D1):1102-9.

42. Rizvi SM, Shakil S, Haneef M. A simple click by click protocol to perform docking: Autodock 4.2 made easy for non-bioinformaticians. EXCLI J. 2013;12:831-57.

43. Li H, Leung K-S, Nakane T, Wong M-H. iview: an interactive WebGL visualizer for protein-ligand complex. BMC Bioinformatics. 2014;15(56): https://doi.org/10.1186/1471-2105-15-56.

44. Cho D-H, Shin J-M. PDB-Ligand: a ligand database based on PDB for the automated and customized classification of ligand-binding structures. Nucleic Acids Res. 2005;33(suppl-1):238-41.

45. Priluskya J, Hodis E, Canner D, Decatur WA, Oberholser K, MartzE, Berchanski A, Harel M, Sussman JL. Proteopedia: A status report on the collaborative, 3D web-encyclopedia of proteins and other biomolecules. J Struct Biol. 2011;175(2):244-52.

46. Desaphy J, G GB, Rognan D, Kellenberger E. sc-PDB: a 3D-database of ligandable binding sites-10 years on. Nucleic Acids Res. 2014;43(Database issue):399-404.

47. Stierand K, Rarey M. Poseview - molecular interaction patterns at a glance. J Cheminformatics. 2010;2(Suppl 1):50.

48. Kasahara K, Kinoshita K. GIANT: pattern analysis of molecular interactions in 3D structures of protein-small ligand complexes. BMC Bioinformatics. 2014;15(12):. https://doi.org/10.1186/1471-2105-15-12.

49. Arenas-Salinas M, Ortega-Salazar S, Gonzales-Nilo F, Pohl E, Holmes DS, Quatrini R. AFAL: a web service for profiling amino acids surrounding ligands in proteins. J Comput Aided Mol Des. 2014;28(11):1069-76.

50. Ertl P. Molecular structure input on the web. J Cheminformatics. 2010;2(1): https://doi.org/10.1186/1758-2946-2-1.

51. Huber W, Carey VJ, Long L, Falcon S, Gentleman R. Graphs in molecular biology. BMC Bioinformatics. 2007;8(Suppl 6):. https://doi.org/10.1186/ 1471-2105-8-s6-s8.

52. Dogrusoz U, Cetintas A, Demir E, Babur O. Algorithms for effective querying of compound graph-based pathway databases. BMC Bioinformatics. 2009;10(376): https://doi.org/10.1186/1471-2105-10-376.

53. Have $\mathrm{CT}$, Jensen $\mathrm{L}$. Are graph databases ready for bioinformatics? Bioinformatics. 2013:29(24):3107-8.

54. Hoksza D, Jelínek J. Using Neo4j for Mining Protein Graphs: A Case Study. In: International Workshop on Database and Expert Systems Applications (DEXA); 2015. p. 230-4. https://doi.org/10.1109/dexa.2015.59.

55. Fabregat $A$, Korninger $F$, Viteri $G$, Sidiropoulos $K$, Marin-Garcia $P$, Ping $P$, Wu G, Stein L, D'Eustachio P, Hermjakob H. Reactome graph database: Efficient access to complex pathway data. PLoS Comput Biol. 2018;14(1): $1-13$.

\section{Publisher's Note}

Springer Nature remains neutral with regard to jurisdictional claims in published maps and institutional affiliations.

Ready to submit your research? Choose BMC and benefit from:

- fast, convenient online submission

- thorough peer review by experienced researchers in your field

- rapid publication on acceptance

- support for research data, including large and complex data types

- gold Open Access which fosters wider collaboration and increased citations

- maximum visibility for your research: over $100 \mathrm{M}$ website views per year

At BMC, research is always in progress.

Learn more biomedcentral.com/submissions 